\title{
Efficacy, effectiveness, and safety of herpes zoster vaccines in adults aged 50 and older: systematic review and network meta-analysis
}

\author{
Andrea C Tricco, ${ }^{1,2}$ Wasifa Zarin, ${ }^{1}$ Roberta Cardoso, ${ }^{1}$ Areti-Angeliki Veroniki, ${ }^{1}$ Paul A Khan, ${ }^{1}$ \\ Vera Nincic, ${ }^{1}$ Marco Ghassemi, ${ }^{1}$ Rachel Warren, ${ }^{1}$ Jane P Sharpe, ${ }^{1}$ Andrea V Page, ${ }^{3,4}$ \\ Sharon E Straus ${ }^{4,5}$
}

${ }^{1}$ Knowledge Translation

Program, Li Ka Shing Knowledge Institute, St Michael's Hospital,

209 Victoria Street, East

Building, Toronto, M5B 1W8,

ON, Canada

2Epidemiology Division, Dalla Lana School of Public Health,

University of Toronto, 155

College Street, Toronto, M5T

3M7, ON, Canada

${ }^{3}$ Division of Infectious Diseases,

Mount Sinai Hospital, Joseph

and Wolf Lebovic Health

Complex, Toronto, ON, Canada

${ }^{4}$ Department of Medicine,

University of Toronto, Toronto,

ON, Canada

${ }^{5}$ St Michael's Hospital, Toronto,

ON, Canada

Correspondence to: A C Tricco

triccoa@smh.ca

(or@atricco on Twitter;

ORCID 0000-0002-4114-8971)

Additional material is published

online only. To view please visit

the journal online.

Cite this as: BMJ 2018;363:k4029 http://dx.doi.org/10.1136/bmi.k4029

Accepted: 3 September 2018

\section{ABSTRACT}

OBJECTIVE

To compare the efficacy, effectiveness, and safety of the herpes zoster live attenuated vaccine with the herpes zoster adjuvant recombinant subunit vaccine or placebo for adults aged 50 and older.

DESIGN

Systematic review with bayesian meta-analysis and network meta-analysis.

\section{DATA SOURCES}

Medline, Embase, and Cochrane Library (inception to January 2017), grey literature, and reference lists of included studies.

\section{ELIGIBILITY CRITERIA FOR STUDY SELECTION}

Experimental, quasi-experimental, and observational studies that compared the live attenuated vaccine with the adjuvant recombinant subunit vaccine, placebo, or no vaccine in adults aged 50 and older. Relevant outcomes were incidence of herpes zoster (primary outcome), herpes zoster ophthalmicus, postherpetic neuralgia, quality of life, adverse events, and death.

\section{RESULTS}

27 studies (22 randomised controlled trials) including 2044504 patients, along with 18 companion reports, were included after screening 2037 titles and abstracts, followed by 175 full text articles. Network meta-analysis of five randomised controlled trials found no statistically significant differences between the live attenuated vaccine and placebo for incidence of laboratory confirmed herpes zoster. The adjuvant recombinant subunit vaccine, however, was statistically superior to both the live attenuated vaccine (vaccine efficacy $85 \%, 95 \%$ credible interval $31 \%$ to $98 \%)$ and placebo $(94 \%, 79 \%$ to $98 \%)$. Network meta-analysis of 11 randomised controlled trials showed the adjuvant recombinant

\section{WHAT IS ALREADY KNOWN ON THIS TOPIC}

Two vaccines against herpes zoster (shingles) are available: a live attenuated vaccine and an adjuvant recombinant subunit vaccine

No trials have directly compared the safety, efficacy, and effectiveness of these vaccines

\section{WHAT THIS STUDY ADDS}

The adjuvant recombinant subunit vaccine might prevent more cases of herpes zoster than the live attenuated vaccine

Compared with the live attenuated vaccine, however, the recombinant subunit vaccine might carry a greater risk of adverse events at injection sites subunit vaccine to be associated with statistically more adverse events at injection sites than the live attenuated vaccine (relative risk $1.79,95 \%$ credible interval 1.05 to 2.34 ; risk difference $30 \%, 95 \%$ credible interval $2 \%$ to $51 \%)$ and placebo $(5.63,3.57$ to 7.29 and $53 \%, 30 \%$ to $73 \%$, respectively). Network meta-analysis of nine randomised controlled trials showed the adjuvant recombinant subunit vaccine to be associated with statistically more systemic adverse events than placebo $(2.28,1.45$ to 3.65 and $20 \%, 6 \%$ to $40 \%$, respectively).

\section{CONCLUSION}

Using the adjuvant recombinant subunit vaccine might prevent more cases of herpes zoster than using the live attenuated vaccine, but the adjuvant recombinant subunit vaccine also carries a greater risk of adverse events at injection sites.

PROTOCOL REGISTRATION

Prospero CRD42017056389.

\section{Introduction}

Herpes zoster, or shingles, is a neurocutaneous disease that occurs through reactivation of latent varicella zoster virus (the virus that causes chicken pox). ${ }^{1} \mathrm{~A}$ quarter of the population is at risk of developing herpes zoster during their lifetime, ${ }^{2-6}$ and two thirds of people with the disease are aged 50 years or older. ${ }^{7}$ The morbidity from herpes zoster increases with age. ${ }^{8}$ A systematic review reported higher case fatality rates for those aged 65 or more (61 per 100000) compared with those aged 45-65 (2 per 100000). ${ }^{1}$ In most high income countries, a live attenuated, injectable vaccine is available for the prevention of herpes zoster in adults aged 50 and older. ${ }^{9}$ However, vaccine efficacy decreases in those aged 70 and more, ${ }^{10}{ }^{11}$ and vaccine use is contraindicated in those with immunosuppression. ${ }^{12} 13$ Recently, a new adjuvant recombinant subunit vaccine against herpes zoster has been approved in Canada, ${ }^{14} 15$ the United States, ${ }^{16}$ Europe, and Japan. ${ }^{17}$

A Cochrane review compared the live attenuated vaccine with the new adjuvant recombinant subunit vaccine but excluded trials with participants aged less than 60 years as well trials with immunosuppressed people. ${ }^{18}$ As a result, one of the largest randomised controlled trials with 22000 participants aged 50-59 years was excluded. ${ }^{11}$ The review also excluded observational studies, which are important for the examination of vaccine safety. ${ }^{19}$ Furthermore, since no head-to-head trials have compared the live attenuated vaccine with the new adjuvant recombinant subunit 
vaccine, an analysis that indirectly compares the herpes zoster vaccines through the common comparator placebo is required.

In this systematic review and network meta-analysis we compared the efficacy, effectiveness, and safety of the live attenuated herpes zoster vaccine with the adjuvant recombinant subunit vaccine, placebo, or no vaccine in those aged 50 years and older.

\section{Methods}

Protocol

A protocol was prepared in accordance with the Cochrane Handbook ${ }^{20}$ and the Preferred Reporting Items for Systematic Reviews and Meta-analysis for Protocols (PRISMA-P). ${ }^{21}$ All members of the team, as well as the review commissioners from the National Advisory Committee on Immunizations (NACI) and the Public Health Agency of Canada reviewed the draft protocol. The final version of the protocol was registered with PROSPERO. ${ }^{22}$ Results are reported using the PRISMA extension to network meta-analysis ${ }^{23}$ and the International Society for Pharmacoeconomics and Outcomes Research tool. ${ }^{24-28}$

\section{Eligibility criteria}

We defined study eligibility criteria using the PICOS (population, intervention, comparator, outcome, and study) design approach ${ }^{29}$ :

Population-adults aged 50 years and older

Intervention-live attenuated injectable herpes zoster vaccine

Comparator(s)_adjuvant recombinant subunit herpes zoster vaccine, placebo, or no vaccine. Studies that compared the same vaccine at different dosages, potencies, and routes of being administered were eligible for inclusion. We excluded experimental herpes zoster vaccines

Outcomes-vaccine efficacy for prevention of herpes zoster (primary outcome) was assessed on the basis of estimates from randomised controlled trials. Secondary outcomes included vaccine efficacy and effectiveness against post-herpetic neuralgia and herpes zoster ophthalmicus; quality of life measured using the EuroQol (EQ5D), Health Utilities Index Mark 2 (HUI2), Health Utilities Index Mark 3 (HUI3), or Short Form 6 Dimensions (SF6D); and vaccine safety, including adverse events at the injection site, systemic adverse events, serious adverse events, withdrawal of participants as a result of adverse events, potential immune mediated diseases, and death. Supplementary appendix S1 defines the study outcomes.

Study designs-experimental trials (randomised controlled, quasi-randomised controlled, nonrandomised controlled), quasi-experimental studies (interrupted time series, controlled before and after), and observational studies (cohort, case-control) were eligible for inclusion. We excluded study designs without a comparator group (eg, case series, cross sectional), reviews, and pooled analyses.
All study periods and durations of follow-up were eligible. No other limitations, including language and location of publication, were imposed; both published and unpublished literature were eligible for inclusion.

\section{Information sources and literature search}

One librarian (Elise Cogo) developed comprehensive literature searches of electronic bibliographic databases for Medline, Embase, and the Cochrane Library. Another librarian (Jessie McGowan) then reviewed the search strategy using the Peer Review of Electronic Search Strategies checklist. ${ }^{30}$ (Appendix S2 provides the combined search strategy for all three databases.) A library technician (Alissa Epworth) searched the electronic databases from inception to 19 January 2017, exported citations into an EndNote library, and removed duplicates. AE also conducted a supplementary search of grey literature (ie, studies that are difficult to locate and unpublished studies) using the guide produced by the Canadian Agency for Drugs and Technologies in Health. ${ }^{31}$ Grey literature sources that were searched included study registries (eg, ClinicalTrials.gov), grey literature databases (eg, SIGLE), conference abstracts, and theses and dissertations (see appendix S3). The reference lists of included studies and relevant reviews were scanned ${ }^{918}$ and experts from NACI consulted on specific content.

\section{Screening process}

To ensure reliability, the research team screened a random sample of 50 titles and abstracts before actual screening. ${ }^{20}$ As the inter-rate agreement was $76 \%$, the reviewers independently screened titles and abstracts in pairs (WZ, RC, PK, VN, MG, RW, JPS). The inter-rater agreement for title and abstract screening was 91\%. A random sample of 100 full text articles were initially screened to establish at least $75 \%$ inter-rater agreement before screening of full texts. Pairs of reviewers (WZ, RC, PK, VN, MG, RW, JPS) then independently screened full text articles; the inter-rater agreement was $80 \%$. A third reviewer resolved discrepancies, with input from experts on clinical content (SES, AVP) as needed. An online screening tool, Synthesi.SR, developed by the Knowledge Translation Program, was used for all levels of screening and training exercises. ${ }^{32}$

\section{Data items and abstraction process}

We extracted data on study characteristics (eg, duration of follow-up, study design, country, multicentre sites versus single site), patient characteristics (eg, mean age, age range, history of herpes zoster, history of chickenpox related comorbidities, overall health status according to the NACI criteria for immune compromising conditions (see appendix S4)), and outcome measures (herpes zoster incidence, postherpetic neuralgia defined as pain continuing for 90 days or longer after the onset of a rash, herpes zoster ophthalmicus, adverse events, quality of life, and death). Outcome results were only abstracted for the longest duration of follow-up, as this is the most conservative approach. ${ }^{20} \mathrm{~A}$ draft data collection form 
was established after consultation with the research team, including clinicians and methodologists.

Before data abstraction, the review team tried out the data abstraction form on a random sample of five articles. $^{20}$ Subsequently, pairs of reviewers (WZ, RC, PK, VN, MG, RW, JPS) independently abstracted the included studies. A third reviewer (WZ) compiled the statistical files and resolved discrepancies between reviewers, ensuring data accuracy and consistency. Authors were contacted for missing information and clarification (eg, whether patient populations overlapped in publications that used the same administrative databases).

\section{Risk of bias assessment}

Pairs of reviewers (PK, VN, MG) independently appraised risk of bias in each study using the Cochrane risk of bias tool ${ }^{33}$ for randomised controlled trials and quasi-randomised controlled trials, the Newcastle Ottawa $\mathrm{Scale}^{34}$ for observational studies, and the Cochrane Effective Practice and Organisation of Care Risk-of-Bias Tool ${ }^{35}$ for non-randomised trials and quasiexperimental studies. Only reviewers experienced in using the tools were involved at this step. A third reviewer (RC) consistently resolved discrepancies.

\section{Statistical analysis}

A bayesian approach was used to conduct metaanalyses and network meta-analyses. ${ }^{36}$ Analyses were carried out in a bayesian environment, which allows for the inclusion of an informative prior in the model variable for the between study variance ${ }^{37}$; as well as the implementation of hierarchical models that preserve the treatment-dose relation in a dose effects analysis. ${ }^{38}$ Pairwise meta-analysis was conducted when at least two studies examined the same intervention and comparator for a particular outcome. When the treatment nodes formed a connected network of evidence, we did a network meta-analysis to compare the different herpes zoster vaccines using the common comparator, placebo. The treatment nodes included in the analysis were selected by methodologists (ACT, AAV) and clinical experts (SES, AVP), who categorised vaccine dosages across the studies and which were based on the recommended dosage according to Health Canada and vaccine product monographs (table 1). ${ }^{39} 40$ To ensure the transitivity assumption was upheld, we plotted the central tendencies (eg, means, medians) of study and patient characteristics for each treatment comparison for visual inspection. ${ }^{41}$ It was not possible to examine the consistency assumption, since no closed loops were included in the networks. ${ }^{42-45}$

To account for anticipated methodological and clinical heterogeneity across studies and to achieve the highest generalisability in the pooled treatment effects, we applied a random effects model in both metaanalysis and network meta-analysis. Furthermore, to increase power in the heterogeneity estimation for each network, we assumed a common within network $\tau 2$ across treatment comparisons in both meta-analysis and network meta-analysis models. This assumption was clinically reasonable as similar treatments were included.

Analyses were conducted using OpenBUGS (version 3.2.3 rev 1012) assuming a half-normal prior for the between study standard deviation $(\tau \sim N(0,1), \tau>0)$ for the primary analysis, and using vague priors for all remaining model variables. The primary outcome of herpes zoser incidence was also analysed with an informative prior as a sensitivity analysis. ${ }^{37} 46$ We excluded from the analysis those studies reporting zero events across all treatment arms for a particular outcome (see appendix S5). The Markov Chain Monte Carlo method was used to calculate the median odds ratios and 95\% credible intervals. For the comparison of the adjuvant recombinant subunit vaccine with live attenuated vaccine we used the mean control event rate for placebo and the treatment event rate for herpes zoster to transform odds ratio to relative risks. We used established formulas to convert the results for efficacy and effectiveness to vaccine efficacy and effectiveness. $^{47}$ Vaccine efficacy and effectiveness was calculated for doctor or laboratory confirmed herpes zoster, suspected herpes zoster, herpes zoster ophthalmicus, and post-herpetic neuralgia.

We calculated the 95\% prediction interval for all network meta-analysis estimates; this statistic predicts the interval within which the results of a future study might lie. ${ }^{48}$ To examine the hierarchy of vaccines, we used the Surface Under the Cumulative RAnking curves, along with the $95 \%$ credible intervals ${ }^{49}$ and plotted these using the rank heat plot. ${ }^{50}$ To examine potential publication bias and small study effects, we produced an adjusted funnel plot for outcomes including at least 10 studies. $^{51}$ To examine the dose effects of the vaccine, we applied a hierarchical model-the exchangeable subnodes model with subnode consistency. ${ }^{38}$

\begin{tabular}{|c|c|c|c|c|}
\hline Vaccine & Vaccine type & Recommended dosage & Dosage categories & Source \\
\hline $\begin{array}{l}\text { Zostavax, Merck Canada, } \\
\text { Canada }\end{array}$ & Live attenuated & $\begin{array}{l}\text { Single dose comprises entire contents of vial (about } \\
0.65 \mathrm{~mL} \text {, containing varicella zoster virus } \geq 19400 \text { plaque } \\
\text { forming units (PFU)). Administered by subcutaneous } \\
\text { injection }\end{array}$ & $\begin{array}{l}\text { Low dose: } 3500-10000 \mathrm{PFU} \times 1 \\
\text { dose. Standard dose: } 19400-23000 \\
\text { PFU } \times 1 \text { dose. High dose: } \\
40000-200000 \text { PFU } \times 1 \text { dose }\end{array}$ & Product monograph ${ }^{39}$ \\
\hline $\begin{array}{l}\text { Shingrix, GlaxoSmithKline, } \\
\text { Canada }\end{array}$ & $\begin{array}{l}\text { Adjuvant } \\
\text { recombinant subunit }\end{array}$ & $\begin{array}{l}\text { Two doses } 0.5 \mathrm{~mL} \text { each (contains } 50 \mu \mathrm{g} \text { varicella zoster } \\
\text { virus glycoprotein E) with initial dose at month } 0 \text { followed by } \\
\text { second dose anytime between } 2 \text { and } 6 \text { months later. Second } \\
\text { dose is important to ensure maximum vaccine efficacy and } \\
\text { duration of protection against herpes zoster. Administered } \\
\text { by intramuscular injection, preferably in deltoid muscle }\end{array}$ & $\begin{array}{l}\text { Low dose: } 25 \mu \mathrm{g} \times 2 \text { doses. Standard } \\
\text { dose: } 50 \mu \mathrm{g} \times 2 \text { doses. High dose: } \\
100 \mu \mathrm{g} \times 2 \text { doses }\end{array}$ & Product monograph ${ }^{40}$ \\
\hline
\end{tabular}


To examine the robustness of results, we planned several additional analyses a priori: sensitivity analysis restricted to studies with a low risk of bias, subgroup analysis of age (eg, 50-64 years $v \geq 65$ years), health status (healthy adults with no immune compromising conditions referred to as immunocompetent versus adults with at least one immune comprising condition referred to as immunocompromised), sex (women versus men), herpes zoster status (previous herpes zoster infection versus herpes zoster naïve), herpes zoster ophthalmicus (previous herpes zoster ophthalmicus versus none), vaccine status (previous vaccination with herpes zoster live attenuated vaccine versus vaccine naïve), and study design (randomised controlled trials versus non-randomised studies versus randomised controlled trials+non-randomised studies). When data on 10 or more studies were available we examined the duration of follow-up and age distribution through network meta-regression analysis, which was only possible for two outcomes: adverse events at injection sites and suspected herpes zoster. We only considered additional analyses when the number of studies was greater than the number of treatments for each outcome.

\section{GRADE appraisal}

Technical leads and clinical expert members of the NACI Working Group graded the quality (or certainty) of the available evidence. The results of the GRADE assessments are in the report released by NACI. ${ }^{9}$

\section{Patient and public involvement}

No patients or the public were involved in setting the research question or outcome measures, nor were they involved in the design and implementation of the study. This is because the commissioning agency and the primary knowledge user, NACI, did not allow for patient engagement, as they had an expedited timeline to make policy decisions on herpes zoster vaccines.

\section{Results}

\section{Literature search}

After screening 2037 titles and abstracts and 175 full text articles, 27 studies $^{10} 11{ }^{52-76}$ providing data on 2044504 patients, and 18 companion reports, ${ }^{77-94}$ met the eligibility criteria (fig 1). Twenty two studies ${ }^{10} 1152$ 56 60-68 70-73 7695 were included in the statistical analysis. The remaining five studies ${ }^{57-7475}$ compared the same vaccine by routes of vaccination, handling of the vaccines, storage of the vaccines, or by time between doses (see summary in appendix S6). Of the included studies, two were unpublished trial registry data. ${ }^{677}$ All were reported in English. Twelve authors were contacted for additional clarification or missing data and nine responded with data clarifications but no additional data.

\section{Study and patient characteristics}

The 27 studies were published between 1998 and 2017: nine in North America (33\%), five in Europe (19\%),

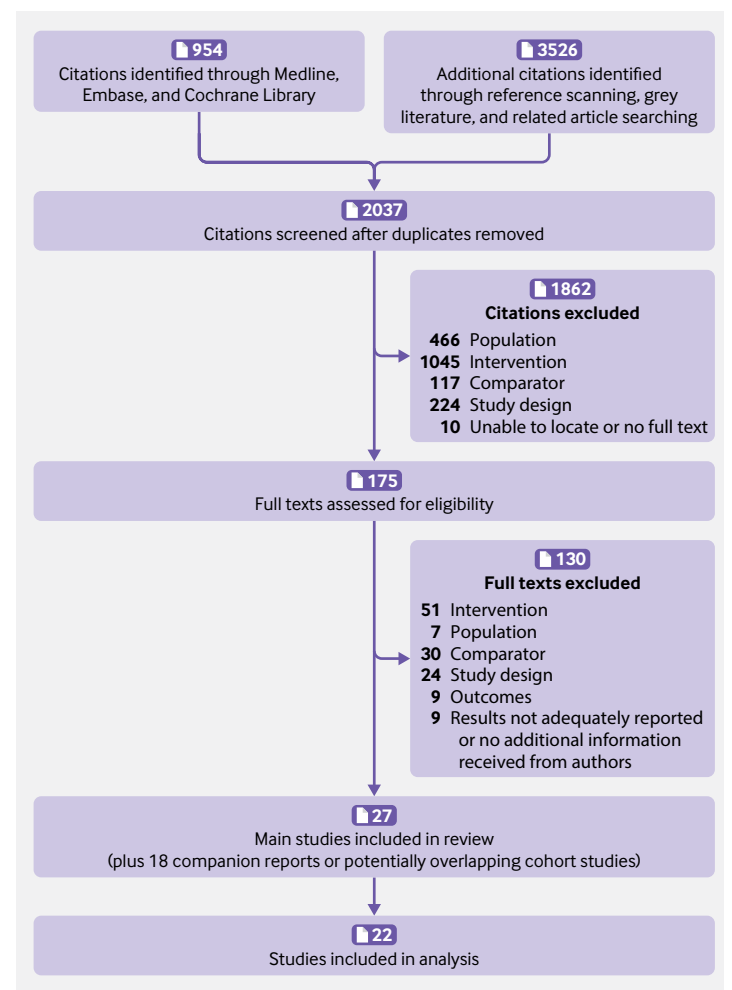

Fig 1 | Study flow diagram

two in Asia (7\%), and 11 across several geographical regions (41\%) (table 2, also see appendix S7). Twenty three of the trials were conducted across multiple study centres (74\%) and 22 studies used a randomised controlled trial study design (81\%). The average study duration was 30.9 months (SD 22.3 months). The live attenuated vaccine was the most commonly examined vaccine type $(70 \%)$ and the incidence of suspected or confirmed herpes zoster was the most commonly examined outcome (81\%).

Twenty three studies (85\%) included patients who were immunocompetent, and 22 studies (81\%) included a sample consisting of more than 50\% women (table 3, also see appendix S8). Twenty four studies (89\%) included patients with no history of herpes zoster, and 18 studies included participants with documented varicella infection (67\%).

\section{Risk of bias results}

Thirteen of the 22 included randomised controlled trials had unclear risk of bias from inadequate reporting of random sequence generation (59\%) and 14 from inadequate reporting of allocation concealment (64\%). In addition, 21 studies had a high risk of "other" biases (95\%), since most of the studies were funded by private industry, and the coauthors included employees from vaccine manufacturers (fig 2, also see appendix S9). The three cohort studies and one case-control study had high to moderate risk of bias for representativeness of the exposed cohort, and for comparability of cohorts in three of the four studies (see appendix S10). The non-randomised trial had an unclear risk of bias for 


\begin{tabular}{|c|c|}
\hline Characteristics & No (\%) of studies \\
\hline \multicolumn{2}{|l|}{ Publication year: } \\
\hline $1998-2002$ & $1(4)$ \\
\hline $2003-0$ & $3(11)$ \\
\hline 2008-12 & $7(26)$ \\
\hline 2013-17 & $16(59)$ \\
\hline \multicolumn{2}{|l|}{ Geographical region: } \\
\hline Asia & $2(7)$ \\
\hline Europe & $5(19)$ \\
\hline North America & $9(33)$ \\
\hline Multi-continent & $11(41)$ \\
\hline \multicolumn{2}{|l|}{ Study setting: } \\
\hline Single centre & $3(11)$ \\
\hline Multicentre & $20(74)$ \\
\hline Not reported & $4(15)$ \\
\hline \multicolumn{2}{|l|}{ Study design: } \\
\hline Case-control & $1(4)$ \\
\hline Non-randomised controlled trial & $1(4)$ \\
\hline Cohort & $3(11)$ \\
\hline Randomised controlled trial & $22(81)$ \\
\hline \multicolumn{2}{|l|}{ Study duration (months)*t: } \\
\hline $0-12$ & $5(19)$ \\
\hline $13-24$ & $7(26)$ \\
\hline $25-36$ & $6(22)$ \\
\hline $37-48$ & $4(15)$ \\
\hline $49-60$ & $2(7)$ \\
\hline$>60$ & $2(7)$ \\
\hline Not reported & $1(4)$ \\
\hline \multicolumn{2}{|l|}{ Frequency of interventions examined: } \\
\hline Live attenuated herpes zoster vaccine & $19(70)$ \\
\hline $\begin{array}{l}\text { Adjuvant recombinant subunit herpes } \\
\text { zoster vaccine }\end{array}$ & $7(26)$ \\
\hline Varicella zoster vaccine & $1(4)$ \\
\hline $\begin{array}{l}\text { Live attenuated herpes zoster vaccine } \\
\text { and pneumovax } 23 \text { vaccine }\end{array}$ & $1(4)$ \\
\hline \multicolumn{2}{|l|}{ Outcomest‡: } \\
\hline Herpes zoster suspected/confirmed & $22(81)$ \\
\hline Herpes zoster ophthalmicus & $3(11)$ \\
\hline Post-herpetic neuralgia & $4(15)$ \\
\hline Injection site adverse event & $21(78)$ \\
\hline Systemic adverse event & $17(63)$ \\
\hline Serious adverse event & $20(74)$ \\
\hline Withdrawals related to adverse event & $17(63)$ \\
\hline Potential immune mediated disease & $4(15)$ \\
\hline Death & $20(74)$ \\
\hline Quality of life & $0(0)$ \\
\hline
\end{tabular}

random sequence generation, allocation concealment, blinding, and contamination, as well as a high risk of “other” bias (see appendix S11).

\section{Statistical analysis results}

Across all analyses, only three comparators were included: live attenuated vaccine, adjuvant recombinant subunit vaccine, and placebo/no vaccine. The transitivity plots suggested that the effect modifiers were balanced across the treatments when these were reported, however, several of the analyses did not have information on all comparisons in the network (see appendix S12). Comparison adjusted funnel plots were generated for the cases of suspected herpes zoster and injection site adverse events outcomes (see appendix S13). Only 11 unique trials existed

\begin{tabular}{|c|c|}
\hline Characteristics & No $(\%)$ of studies \\
\hline \multicolumn{2}{|l|}{ Age group (years): } \\
\hline$\geq 50$ & $11(41)$ \\
\hline$\geq 60$ & $10(37)$ \\
\hline$\geq 70$ & $2(7)$ \\
\hline $50-59$ & $1(4)$ \\
\hline $50-70$ & $1(4)$ \\
\hline $60-70$ & $1(4)$ \\
\hline $60-88$ & $1(4)$ \\
\hline \multicolumn{2}{|l|}{ Immune related health: } \\
\hline Immunocompetent $\dagger$ & $23(85)$ \\
\hline Immunodeficient & $2(7)$ \\
\hline Mixed & $2(7)$ \\
\hline \multicolumn{2}{|l|}{ Proportion women (\%): } \\
\hline$<50$ & $5(19)$ \\
\hline $50-60$ & $13(48)$ \\
\hline $61-75$ & $9(33)$ \\
\hline \multicolumn{2}{|l|}{ History of herpes zoster: } \\
\hline Yes & $1(4)$ \\
\hline No & $24(89)$ \\
\hline Not reported & $2(7)$ \\
\hline \multicolumn{2}{|c|}{ History of varicella zoster: } \\
\hline Yes & $18(67)$ \\
\hline No & $1(4)$ \\
\hline Not reported & $8(30)$ \\
\hline
\end{tabular}

for both of these outcomes, resulting in low power to examine publication bias and small study effects. Although the funnel plot for injection site adverse events was considered to be symmetrical, the funnel plot for suspected herpes zoster was asymmetrical. Further examination revealed three trials ${ }^{616670}$ with large standard errors and negative centred effect sizes, so a sensitivity analysis was done excluding these three trials. The results in table 4 and table 5 and in figure 3 and figure 4 are based on randomised controlled trials that included immunocompetent or immunocompromised patients, or both.

\section{Efficacy and effectiveness results}

\section{Laboratory or doctor confirmed herpes zoster}

Five randomised controlled trials including 90605 immunocompetent and immunocompromised patients were included in the network meta-analysis of laboratory or doctor confirmed cases of herpes zoster. The adjuvant recombinant subunit vaccine was statistically superior to placebo (vaccine efficacy 94\%, 95\% credible interval $79 \%$ to $98 \%$ ) and the live attenuated vaccine $(85 \%, 31 \%$ to $98 \%)$, whereas the live attenuated vaccine was not statistically different from placebo (table 4 and table 5). These results were similar in the sensitivity analysis restricted to immunocompetent patients only (see appendix S14). Four randomised controlled trials were included in the dose effects analysis, and only the adjuvant recombinant subunit vaccine was statistically superior to placebo (see appendix S23), which was consistent in additional network meta-analysis restricted to four randomised controlled trials including patients with no history of herpes zoster, and restricted to four randomised controlled trials with low risk of bias on 


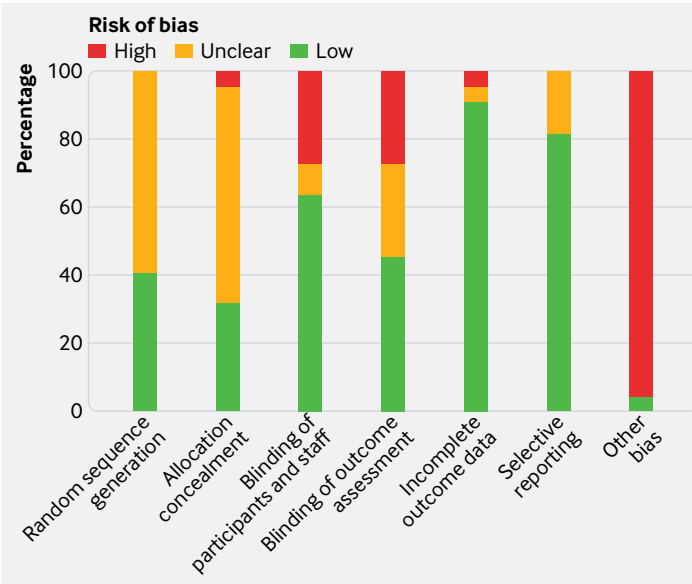

Fig 2 | Distribution of Cochrane Collaboration Risk of Bias assessment ( $\mathrm{n}=22$ randomised controlled trials). The "other bias" item was scored as high risk of bias when studies were funded by private industries and included authors who are employed by vaccine manufacturers

random sequence generation. Additional analyses based on all study designs (five randomised controlled trials and one cohort study) and the efficacy comparison using informative priors ${ }^{37}$ (five randomised controlled trials) found that the adjuvant recombinant subunit vaccine was statistically superior to placebo and the live attenuated vaccine, and that the live attenuated vaccine was statistically superior to placebo.

\section{Suspected herpes zoster}

Seven randomised controlled trials including 91840 immunocompetent and immunocompromised patients were included in the network meta-analysis of suspected herpes zoster infection. The adjuvant recombinant subunit vaccine was statistically superior to placebo (vaccine efficacy 77\%, 95\% credible interval $66 \%$ to $84 \%$ ) and the live attenuated vaccine $(63 \%, 43 \%$ to $80 \%)$, and the live attenuated vaccine was statistically superior to placebo $(39 \%$, $7 \%$ to $52 \%$; table 4 and table 5 ). These results were consistent in additional analyses, including all study designs (seven randomised controlled trials, three cohort studies, one case-control study), network meta-regression on duration of follow-up (seven randomised controlled trials, three cohort studies, one case-control study), using an informative prior $^{37}$ (seven randomised controlled trials), sensitivity analysis restricted to immunocompetent (and potentially immunocompetent) patients (six randomised controlled trials), sensitivity analysis restricted to immunocompetent patients (four randomised controlled trials), as well as a sensitivity analysis excluding three trials ${ }^{616670}$ to explain the asymmetrical funnel plot. (Also see appendix S15.)

\begin{tabular}{|c|c|c|c|c|c|c|c|}
\hline \multirow[b]{2}{*}{$\begin{array}{l}\text { Treatment comparison, } \\
\text { reference }\end{array}$} & \multirow[b]{2}{*}{$\begin{array}{l}\text { No of studies } \\
\text { (No of patients) }\end{array}$} & \multicolumn{2}{|c|}{$\begin{array}{l}\text { Study group (No of events/ } \\
\text { total No) }\end{array}$} & \multirow{2}{*}{$\begin{array}{l}\text { Odds ratio from direct } \\
\text { and indirect comparisons } \\
(95 \% \mathrm{Crl})(95 \% \mathrm{Prl} \\
\text { indirect comparison only) }\end{array}$} & \multicolumn{2}{|l|}{ Risk ratio } & \multirow[b]{2}{*}{$\begin{array}{l}\text { Vaccine efficacy } \\
\%(95 \% \text { Crl })\end{array}$} \\
\hline & & Treatment & Control & & $\begin{array}{l}\text { Direct comparison } \\
\text { (meta-analysis) }(95 \% \mathrm{Crl})\end{array}$ & $\begin{array}{l}\text { Indirect comparison } \\
(95 \% \mathrm{Crl})(95 \% \mathrm{Prl})\end{array}$ & \\
\hline \multicolumn{8}{|c|}{$\begin{array}{l}\text { Doctor or laboratory confirmed herpes zoster cases: } \\
5 \text { RCTs, } 90605 \text { participants, average follow-up } 28 \text { (range 2-44) months }\end{array}$} \\
\hline $\mathrm{HZ} / \mathrm{su} v \mathrm{ZVL}$ & - & - & - & $\begin{array}{l}0.15(0.02 \text { to } 0.68) \\
(0.01 \text { to } 1.42)^{*}\end{array}$ & - & $\begin{array}{l}0.15(0.02 \text { to } 0.69) \\
(0.01 \text { to } 1.41)^{\star}\end{array}$ & $85(31 \text { to } 98)^{*}$ \\
\hline $\mathrm{HZ} /$ su v placebo $0^{566278}$ & $2(29311)$ & $32 / 14648$ & $458 / 14663$ & $0.06(0.02 \text { to } 0.21)^{\star}$ & $0.06(0.02 \text { to } 0.21)^{\star}$ & - & $94(79 \text { to } 98)^{*}$ \\
\hline ZVL v placebo $0^{10} 117080-87$ & $3(61294)$ & $346 / 30688$ & $741 / 30606$ & $0.43(0.15$ to 1.63$)$ & $0.43(0.16$ to 1.61$)$ & - & $57(-61$ to 84$)$ \\
\hline $\begin{array}{l}\text { Common within network } \\
\text { between study variance }\end{array}$ & - & - & - & - & $0.37(0.02$ to 3.02$)$ & $0.37(0.02$ to 3.10$)$ & - \\
\hline \multicolumn{8}{|c|}{$\begin{array}{l}\text { Suspected herpes zoster cases: } \\
7 \text { RCTs, } 91840 \text { participants, average follow-up } 20 \text { (range 1-44) months }\end{array}$} \\
\hline $\mathrm{HZ} / \mathrm{su} v \mathrm{ZVL}$ & - & - & - & $\begin{array}{l}0.37(0.20 \text { to } 0.57) \\
(0.16 \text { to } 0.71)^{\star}\end{array}$ & - & $\begin{array}{l}0.37(0.20 \text { to } 0.57) \\
(0.16 \text { to } 0.71)^{\star}\end{array}$ & $63(43 \text { to } 80)^{\star}$ \\
\hline $\mathrm{HZ} /$ su v placebo ${ }^{566278}$ & $2(29311)$ & $150 / 14648$ & $643 / 14663$ & $0.23(0.15 \text { to } 0.33)^{\star}$ & $0.23(0.16 \text { to } 0.34)^{\star}$ & & $77(66 \text { to } 84)^{\star}$ \\
\hline ZVL v placebo ${ }^{101161667080-87}$ & $5(62529)$ & $597 / 31307$ & $1000 / 31222$ & $0.60(0.47 \text { to } 0.93)^{*}$ & $0.61(0.48 \text { to } 0.93)^{*}$ & - & $39(7 \text { to } 52)^{\star}$ \\
\hline $\begin{array}{l}\text { Common within network } \\
\text { between study variance }\end{array}$ & - & - & - & - & $0.01(0.00$ to 0.46$)$ & $0.01(0.00$ to 0.49$)$ & - \\
\hline \multicolumn{8}{|c|}{$\begin{array}{l}\text { Herpes zoster ophthalmicus cases: } \\
2 \text { RCTs, } 14209 \text { participants, average follow-up } 25 \text { (range 2-60) months }\end{array}$} \\
\hline $\mathrm{HZ} /$ su v placebot $^{5678}$ & $1(13900)$ & $1 / 6950$ & $6 / 6950$ & $0.12(0.00 \text { to } 0.84)^{\star}$ & $0.12(0.00 \text { to } 0.84)^{\star}$ & - & $88(16 \text { to } 100)^{\star}$ \\
\hline ZVL v placebot ${ }^{70}$ & $1(309)$ & $1 / 207$ & $0 / 102$ & 2.57 (0.08 to 1293.66$)$ & 2.57 (0.08 to 830.34$)$ & - & $\begin{array}{l}-157 \\
(-129266 \text { to } 92)\end{array}$ \\
\hline $\begin{array}{l}\text { Common within network } \\
\text { between study variance }\end{array}$ & - & - & - & - & $0.48(0.00$ to 5.07$)$ & - & - \\
\hline \multicolumn{8}{|c|}{$\begin{array}{l}\text { Post-herpetic neuralgia: } \\
2 \text { RCTs, } 52446 \text { participants, average follow-up } 26 \text { (range 6-46) months }\end{array}$} \\
\hline $\mathrm{HZ} / \mathrm{su}$ v placebot $\mathrm{t}^{5678}$ & $1(13900)$ & $4 / 6950$ & $28 / 6950$ & $0.13(0.04 \text { to } 0.35)^{\star}$ & $0.13(0.04 \text { to } 0.35)^{\star}$ & - & $87(65 \text { to } 96)^{\star}$ \\
\hline ZVL v placebot ${ }^{1080-86}$ & $1(38546)$ & $27 / 19270$ & $80 / 19276$ & $0.33(0.21 \text { to } 0.51)^{\star}$ & $0.34(0.21 \text { to } 0.51)^{\star}$ & - & $66(49 \text { to } 79)^{\star}$ \\
\hline $\begin{array}{l}\text { Common within network } \\
\text { between study variance }\end{array}$ & - & - & - & - & $\begin{array}{l}0.46 \\
(0.00 \text { to } 4.93)\end{array}$ & - & - \\
\hline
\end{tabular}




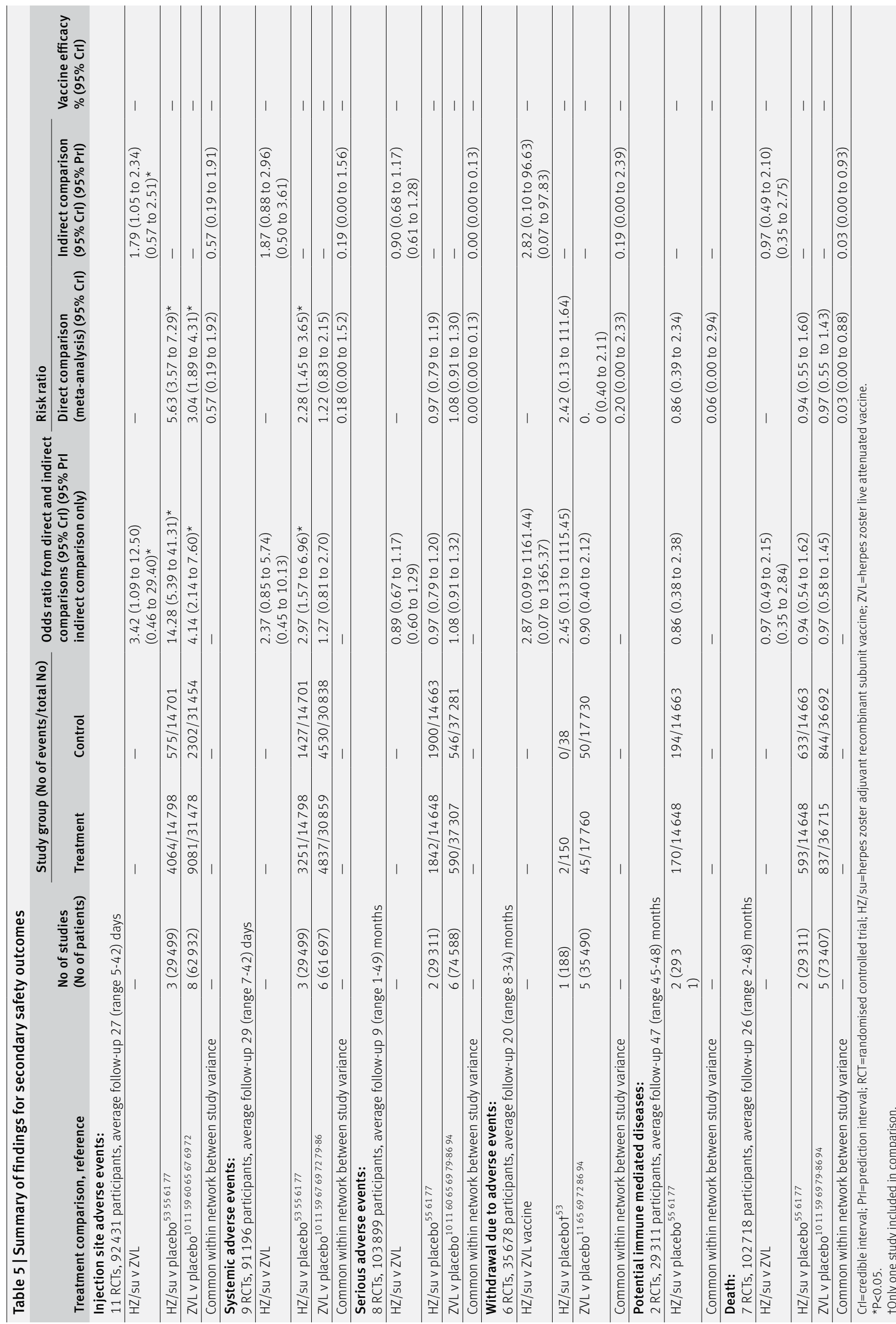




\begin{tabular}{|c|c|c|c|c|c|}
\hline $\begin{array}{l}\text { Outcome } \\
\text { Treatment comparison }\end{array}$ & & $\begin{array}{l}\text { Risk ratio } \\
(95 \% \mathrm{Crl})\end{array}$ & & $\begin{array}{c}\text { Vaccine } \\
\text { efficacy (\%) }\end{array}$ & $\begin{array}{l}\text { Risk ratio } \\
(95 \% \mathrm{Crl})\end{array}$ \\
\hline \multicolumn{6}{|c|}{ Herpes zoster confirmed } \\
\hline $\mathrm{Hz} / \mathrm{su} v \mathrm{ZVL}$ & & $\longrightarrow$ & & 85 & 0.15 (0.02 to 0.69$)$ \\
\hline $\mathrm{HZ} /$ su vplacebo & & $\longrightarrow$ & & 94 & $0.06(0.02$ to 0.21$)$ \\
\hline ZVL v placebo & & $\rightarrow$ & & 57 & $0.43(0.16$ to 1.61$)$ \\
\hline \multicolumn{6}{|c|}{ Herpes zoster suspected } \\
\hline $\mathrm{Hz} / \mathrm{su} v \mathrm{ZVL}$ & & $\rightarrow$ & & 63 & $0.37(0.20$ to 0.57$)$ \\
\hline $\mathrm{HZ} /$ su vplacebo & & $\Rightarrow$ & & 77 & $0.23(0.16$ to 0.34$)$ \\
\hline ZVL v placebo & & - & & 39 & 0.61 (0.48 to 0.93$)$ \\
\hline \multicolumn{6}{|c|}{ Herpes zoster ophthalmicus } \\
\hline $\mathrm{Hz} / \mathrm{su} v \mathrm{ZVL}$ & 4 & - & & 96 & 0.04 (0.00 to 5.80$)$ \\
\hline $\mathrm{HZ} / \mathrm{su}$ vplacebo & & - & & 88 & $0.12(0.00$ to 0.84$)$ \\
\hline ZVL vplacebo & & & & $\begin{array}{ll}-157 \quad 2 & \end{array}$ & $2.57(0.08$ to 830.34$)$ \\
\hline \multicolumn{6}{|l|}{ Post-herpetic neuralgia } \\
\hline $\mathrm{Hz} / \mathrm{su} v \mathrm{ZVL}$ & & $\rightarrow$ & & 62 & $0.38(0.02$ to 8.96$)$ \\
\hline $\mathrm{HZ} / \mathrm{su}$ vplacebo & & $\Leftrightarrow$ & & 87 & $0.13(0.01$ to 1.26$)$ \\
\hline ZVL v placebo & & $\longrightarrow$ & & 66 & 0.34 (0.04 to 2.89$)$ \\
\hline & $4.54 \times 10^{-5} \quad 2.48 \times 10^{-3}$ & $0.14 \quad 1$ & 7.39 & 403.43 & \\
\hline
\end{tabular}

Fig 3 | Forest plot of estimated results from meta-analysis and network meta-analysis of vaccine efficacy outcomes in reducing cases of herpes zoster, herpes zoster ophthalmicus, and post-herpetic neuralgia. $\mathrm{HZ} / \mathrm{su}=$ herpes zoster adjuvant recombinant subunit vaccine; $Z V L=$ herpes zoster live attenuated vaccine

However, in sensitivity analysis restricted to four randomised controlled trials with a low risk bias on random sequence generation, the live attenuated vaccine was no longer statistically different from placebo. In the dose analysis, only standard doses of the live attenuated vaccine and adjuvant recombinant

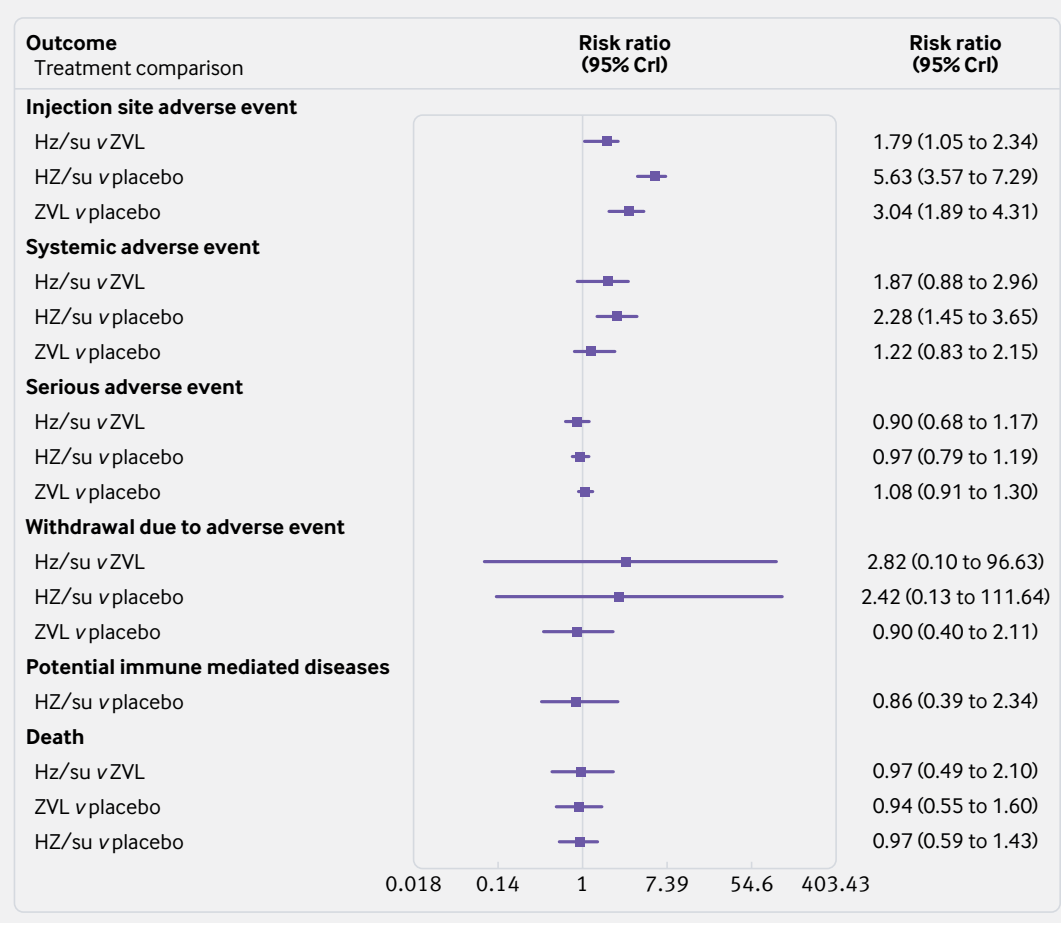

Fig 4 | Forest plot of estimated results from meta-analysis and network meta-analysis of safety outcomes including, injection site, systemic, serious and withdrawal due to adverse events, as well as potential immune mediated diseases and death. $\mathrm{HZ}$ / su=herpes zoster adjuvant recombinant subunit vaccine; $Z V L=$ herpes zoster live attenuated vaccine subunit vaccine were statistically significant compared with placebo (see appendix S23).

\section{Herpes zoster ophthalmicus}

Only two randomised controlled trials including 14209 immunocompetent and immunocompromised patients reported on cases of herpes zoster ophthalmicus; therefore no network meta-analysis was possible. The pairwise meta-analysis showed that the adjuvant recombinant subunit vaccine was statistically superior to placebo (13900 patients, vaccine efficacy 88\%, 95\% credible interval $16 \%$ to $100 \%$ ) and no statistically significant difference was observed between the live attenuated vaccine and placebo (309 patients) (table 4 and table 5, also see appendix S16).

\section{Post-herpetic neuralgia}

Only two randomised controlled trials including 52446 immunocompetent patients reported on postherpetic neuralgia, and the meta-analysis found a statistically significant difference between the adjuvant recombinant subunit vaccine and placebo (13900 patients, vaccine efficacy $87 \%$ 95\% credible interval $65 \%$ to $96 \%$ ), as well as between the live attenuated vaccine and placebo (38546 patients, 66\%, 49\% to 79\%) (table 4 and table 5, also see appendix S17).

\section{Adverse events}

Injection sites-11 randomised controlled trials including 92431 immunocompetent and immunocompromised patients were included in the main network meta-analysis of adverse events at injection sites (eg, redness or swelling). The adjuvant recombinant subunit vaccine was statistically inferior to the live attenuated vaccine (relative risk 1.79, $95 \%$ credible interval 1.05 to 2.34 ) and placebo $(5.63,3.57$ to 7.29$)$, and the live attenuated vaccine was statistically inferior to placebo $(3.04,1.89$ to 4.31; table 4 and table 5). The adjuvant recombinant subunit vaccine was not, however, statistically different from the live attenuated vaccine in additional analyses including patients with no history of herpes zoster (10 randomised controlled trials), network meta-regression on duration of follow-up (11 randomised controlled trials), sensitivity analysis restricted to randomised controlled trials with a low risk of bias on random sequence generation (six randomised controlled trials), sensitivity analysis restricted to immunocompetent and potentially immunocompetent patients (10 randomised controlled trials), and sensitivity analysis restricted to only immunocompetent patients (six randomised controlled trials) (see appendix S18). In sensitivity analysis restricted to five randomised controlled trials with a low risk of bias on allocation concealment, only the adjuvant recombinant subunit vaccine was statistically inferior to placebo. In the dose effect analysis, only the live attenuated vaccine was statistically inferior to placebo (see appendix S23).

Systemic-nine randomised controlled trials including 91196 immunocompetent and 


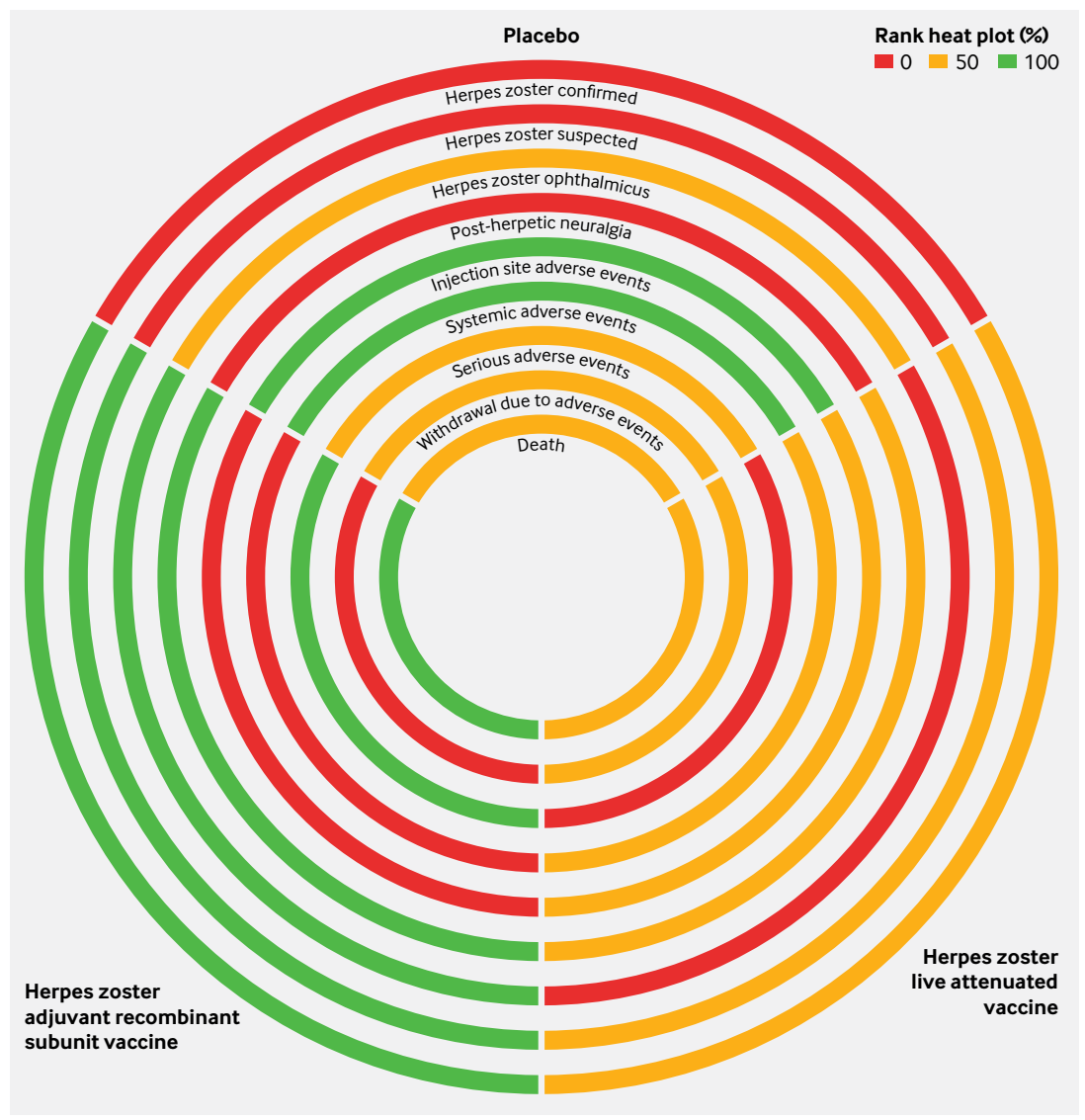

Fig 5 | Rank heat plot, summarising treatment hierarchy across all outcomes. Each circle represents an outcome and has been sectioned into the three interventions, adjuvant, recombinant subunit herpes zoster vaccine, live attenuated herpes zoster vaccine, and placebo. The performance of a particular treatment for each of the outcomes is interpreted based on three colours (worst to best): red ( $0 \%)$, yellow (50\%), and green $(100 \%)$ and immunocompromised patients were included in the network meta-analysis of withdrawal due to adverse events, and none of the comparisons were statistically significant (table 4 and table 5). This was consistent in the dose effect analysis (see appendix S23) and in all additional analyses (see appendix S21).

\section{Potential immune mediated diseases}

Only two randomised controlled trials including 29311 immunocompetent patients were included in the meta-analysis on potential immune mediated diseases (table 4 and table 5); there was no statistical difference between the adjuvant recombinant subunit vaccine and placebo. No additional analyses were possible for this outcome.

\section{Death}

Seven randomised controlled trials including 102718 immunocompetent and immunocompromised patients were included in the network meta-analysis for observed death during the study period, and none of the comparisons were statistically significant (table 4 and table 5). This was consistent in the dose effect analysis (see appendix S23) and in all additional analyses (see appendix S22).

\section{Rank heat plot}

The rank heat plot suggests that the adjuvant recombinant subunit vaccine is the most effective vaccine against herpes zoster, herpes zoster ophthalmicus, and post-herpetic neuralgia, with fewer serious adverse events and deaths than using the live attenuated vaccine or placebo. The live attenuated vaccine is safer for injection site and systemic adverse events, with fewer withdrawals due to adverse events compared with the adjuvant recombinant subunit vaccine (fig 5).

immunocompromised patients were included in the network meta-analysis of systemic adverse events (eg, generalised reactions such as headache and myalgia). The adjuvant recombinant subunit vaccine was statistically inferior to placebo (relative risk 2.28, 95\% credible interval 1.45 to 3.65 ; table 4 and table 5). This was consistent in the additional analysis restricted to eight randomised controlled trials including immunocompetent and potentially immunocompetent patients (see appendix S19). None of the comparisons were, however, statistically significant in the dose effect analysis (see appendix S23) or in any of the other additional analyses.

Serious-eight randomised controlled trials including 103899 immunocompetent and immunocompromised patients were included in the network meta-analysis of serious adverse events (eg, requiring hospital admission), and none of the comparisons were statistically significant (table 4 and table 5). This was consistent in the dose effect analysis (see appendix S23) and in all additional analyses (see appendix S20).

Withdrawal due to adverse events-six randomised controlled trials including 35678 immunocompetent

\section{Discussion}

The results suggest that the adjuvant recombinant subunit vaccine is superior to the live attenuated vaccine for the prevention of herpes zoster infection, as measured by laboratory or doctor confirmed cases and suspected cases. Owing to a lack of data, the superiority of the adjuvant recombinant subunit vaccine over the live attenuated vaccine in reducing the number of cases of herpes zoster ophthalmicus and post-herpetic neuralgia is inconclusive. The adjuvant recombinant subunit vaccine was, however, associated with more adverse events at injection sites than the live attenuated vaccine. On the basis of the limited indirect evidence available, no statistically significant differences were shown between the vaccines for serious adverse events, withdrawals due to adverse events, potential immune mediated diseases, and death. A current randomised controlled trial comparing the immunogenicity and safety of the adjuvant recombinant subunit vaccine with the live attenuated vaccine will provide direct evidence on the relative safety of the two vaccines. ${ }^{96}$ As such, the results of this systematic review will need 
to be updated with evidence from this trial, as well as any additional new trials completed after the literature search. Differences between the dosages of the vaccine were not observed, suggesting the standard doses are appropriate for clinical use.

\section{Strengths and limitations of this study}

This systematic review has several strengths. As no trials currently compare the safety and effectiveness of the adjuvant recombinant subunit vaccine and live attenuated vaccine directly, this systematic review tackles an important evidence gap by indirectly comparing the two available vaccines using valid meta-analysis methods to inform clinicians and policy makers. We followed international guidelines on the conduct and reporting of systematic reviews and network meta-analyses, including the Cochrane Handbook, ${ }^{20}$ International Society for Pharmacoeconomics and Outcomes Research tool, ${ }^{242526}$ and PRISMA statements. ${ }^{21} 2728$ Several limitations do, however, relate to the included studies as they might have been affected by several types of bias, such as from inadequate reporting of random sequence generation, allocation concealment, and comparability of cohorts. Also, several of the planned analyses were not conducted owing to insufficient data, such as subgroup analysis on the age of participants, network meta-regression for duration of follow-up, or analyses restricted to immunocompromised patients across all outcomes. Furthermore, asymmetry was observed in the funnel plot for the suspected herpes zoster outcome, which is likely caused by variation in study characteristics; the sample sizes ranged from 309 to 762 patients in four studies and from 13900 to 766330 patients in another seven studies. After excluding three trials with large standard errors and negative centred effect sizes, the results from the metaanalysis and network meta-analysis were unchanged.

\section{Comparison with other studies}

The findings reported here are consistent with a review of the evidence conducted by the Centers for Disease Control and Prevention, which recommended the adjuvant recombinant subunit vaccine for immunocompetent adults aged 50 years and older. ${ }^{97}$ Although a literature review of the evidence was carried out, the CDC did not conduct a systematic review or network meta-analysis. The CDC also did a cost analysis and found that the adjuvant recombinant subunit vaccine prevented more disease at lower overall costs than the live attenuated vaccine. However, an additional cost effectiveness analysis might provide further clarity. Importantly, the adjuvant recombinant subunit vaccine requires two doses to be administered intramuscularly at 0 and 2-6 months, whereas the live attenuated vaccine requires a single subcutaneous dose. As such, a comparison of cost, including vaccine route of being administered, as well as storage and handling is required. A retrospective cohort study published after the literature search found the live attenuated vaccine to be effective, but immunity waned after five years. ${ }^{98}$ The study also found that as people aged, the vaccine was less effective.

The results of this systematic review indicate that the adjuvant recombinant subunit vaccine is likely more effective than the live attenuated vaccine for preventing herpes zoster. Additionally, the dose effects analysis suggested that current standard doses are appropriate. As such, clinicians and policy makers can use these results to inform their recommendations about these vaccines to patients and the general public.

\section{Policy implications}

Several unanswered questions remain. For example, it is unclear whether the adjuvant recombinant subunit vaccine is effective for immunocompromised people. It also remains to be confirmed whether the live attenuated vaccine is more effective than the adjuvant recombinant subunit vaccine for protection against post-herpetic neuralgia, whether a booster dose is required, whether the adjuvant recombinant subunit vaccine is comparatively cost effective considering it needs to be administered in two doses, and what the safety implications are for the recombinant subunit vaccine, given that it comprises an adjuvant. Furthermore, many of the studies had small sample sizes, especially the randomised controlled trials. Future trials should include larger sample sizes and examine quality of life, the incidence of herpes zoster ophthalmicus and post-herpetic neuralgia, and potential immune mediated diseases.

\section{Conclusions}

The adjuvant recombinant subunit vaccine is likely superior to the live attenuated vaccine against herpes zoster; however, the adjuvant recombinant subunit vaccine also carries a greater risk of adverse events at injection sites. No statistically significant differences were identified between the two vaccines for serious adverse events, withdrawals related to adverse events, and death. Differences between the dosages of the vaccines were not observed, suggesting that standard doses are appropriate.

The National Advisory Committee on Immunizations (NACl), which reports to the Public Health Agency of Canada commissioned this systematic review. We thank the NACI Herpes Zoster Working Group for providing input and guidance on the research question, study eligibility criteria, and search strategy; Elise Cogo for developing the search strategy; Jessie McGowan for peer reviewing the search strategy; Alissa Epworth for library support, including performing the database and grey literature searches and obtaining full text papers; Myanca Rodrigues and Ba' Pham for help with converting the results to vaccine efficacy; and Shazia Siddiqui and Krystle Amog for formatting the manuscript, as well as providing logistical and administrative support.

Contributors: ACT obtained funding, conceived the research, participated in pilot testing the screening and data abstraction forms, helped conceptualise the analysis, interpreted the data, and wrote the first draft of the manuscript. ACT is the guarantor. WZ coordinated the study, screened citations and full texts, resolved discrepancies, verified data accuracy and analysis, prepared the tables and figures, and helped draft sections of the manuscript. RC helped coordinate the study, screened citations and full texts, abstracted data, resolved discrepancies in risk of bias assessments, and reviewed the manuscript. AAV analysed and helped interpret the data and reviewed the manuscript. PAK, VN, MG, RW, and JPS helped to screen citations 
and full texts, abstracted data, and reviewed the manuscript. PAK, VN, and MG carried out risk of bias assessment. AVP provided clinical content expertise, verified categorisation of patient population health condition for analysis, and reviewed the manuscript. SES obtained funding, provided clinical content expertise, helped conceive the research, and reviewed the manuscript. The corresponding author attests that all listed authors meet authorship criteria and that no others meeting the criteria have been omitted.

Funding: This study was funded by the Canadian Institutes of Health Research Drug Safety and Effectiveness Network (DNM-137713). ACT is funded by a tier 2 Canada research chair in knowledge synthesis. SES is funded by a tier 1 Canada research chair in knowledge translation. The funder had no input into the study design; collection, analysis, and interpretation of data; writing of the manuscript; and decision to submit the paper for publication.

Competing interests: All authors have completed the ICMJE uniform disclosure form at www.icmje.org/coi_disclosure.pdf and declare that all authors had financial support from the Canadian Institutes of Health Research Drug Safety and Effectiveness Network (DNM-137713); authors have no financial relationships with any organisations that might have an interest in the submitted work in the previous three years; and no other relationships or activities to declare that could appear to have influenced the submitted work.

Ethical approval: Not required.

Data sharing: The full dataset and statistical code are available from the corresponding author on reasonable request.

Transparency: The lead author (ACT) affirms that the manuscript is an honest, accurate, and transparent account of the study being reported; that no important aspects of the study have been omitted; and that any discrepancies from the study as planned (and, if relevant, registered) have been explained.

This is an Open Access article distributed in accordance with the terms of the Creative Commons Attribution (CC BY 4.0) license, which permits others to distribute, remix, adapt and build upon this work, for commercial use, provided the original work is properly cited. See: http://creativecommons.org/licenses/by/4.0/.

1 Bricout H, Haugh M, Olatunde O, Prieto RG. Herpes zosterassociated mortality in Europe: a systematic review. BMC Public Health 2015:15:466. doi:10.1186/s12889-015-1753-y

2 Guidelines for the management of shingles. report of a working group of the British Society for the Study of Infection (BSSI). J Infect 1995;30:193-200.

3 Edmunds WJ, Brisson M, Rose JD. The epidemiology of herpes zoster and potential cost-effectiveness of vaccination in England and Wales. Vaccine 2001;19:3076-90 doi:10.1016/S0264-410X(01)00044-5

4 Gross G, Schöfer H, Wassilew S, et al. Herpes zoster guideline of the German Dermatology Society (DDG). J Clin Virol 2003;26:277-89, discussion 291-3. doi:10.1016/S13866532(03)00005-2

5 Lee VK, Simpkins L. Herpes zoster and postherpetic neuralgia in the elderly. Geriatr Nurs 2000;21:132-5, quiz 136. doi:10.1067/mgn.2000.108260

6 Thiry N, Beutels P, Shkedy Z, et al. The seroepidemiology of primary varicella-zoster virus infection in Flanders (Belgium). Eur Pediatr 2002:161:588-93 doi:10.1007/s00431-002-1053-2

7 Yawn BP, Saddier P, Wollan PC, St Sauver JL, Kurland MJ, Sy LS. A population-based study of the incidence and complication rates of herpes zoster before zoster vaccine introduction. Mayo Clin Proc 2007:82:1341-9. doi:10.4065/82.11.1341

8 Rimland D, Moanna A. Increasing incidence of herpes zoster among Veterans. Clin Infect Dis 2010;50:1000-5. doi:10.1086/651078

9 An Advisory Committee Statement (ACS) National Advisory Committee on Immunization (NACI)- Update on the Use of Herpes Zoster Vaccine. 2014. www.canada.ca/content/dam/phac-aspc/ documents/services/publications/healthy-living/update-use-herpeszoster-vaccine/hzv-vcz-eng.pdf.

10 Oxman MN, Levin MJ, Johnson GR, et al, Shingles Prevention Study Group. A vaccine to prevent herpes zoster and postherpetic neuralgia in older adults. N Engl J Med 2005;352:2271-84 doi:10.1056/NEJMoa051016

11 Schmader KE, Levin MJ, Gnann JW.Jr, et al. Efficacy, safety, and tolerability of herpes zoster vaccine in persons aged $50-59$ years. Clin Infect Dis 2012;54:922-8. doi:10.1093/cid/cir970

12 Gershon AA, Gershon MD, Breuer J, Levin MJ, Oaklander AL, Griffiths PD. Advances in the understanding of the pathogenesis and epidemiology of herpes zoster. J Clin Virol 2010;48(Suppl 1):S2-7. doi:10.1016/S1386-6532(10)70002-0
13 Hales CM, Harpaz R, Ortega-Sanchez I, Bialek SR, Centers for Disease Control and Prevention (CDC). Update on recommendations for use of herpes zoster vaccine. MMWR Morb Mortal Wkly Rep 2014;63:729-31.

14 SHINGRIX approved in Canada as the first non-live adjuvanted vaccine to help protect against shingles. 2017. http://ca.gsk.com/en$\mathrm{ca} /$ media/press-releases/2017/shingrix-approved-in-canada-as-thefirst-non-live-adjuvanted-vaccine-to-help-protect-against-shingles/.

15 GSK announces first approval of Shingrix in Canada- The only shingles vaccine to achieve $\geq 90 \%$ efficacy in adults aged 50 and over. GlaxoSmithKline, 2017.

16 Shingrix approved in the US for prevention of shingles in adults aged 50 and over- Pooled clinical trial results showed $>90$ percent efficacy across all age groups, GlaxoSmithKline 2017.

17 Shingrix approved in Europe and Japan for the prevention of shingles in adults aged 50 and over- The only shingles vaccine to achieve $\geq 90 \%$ efficacy across all age groups studied*, GlaxoSmithKline 2018.

18 Gagliardi AM, Andriolo BN, Torloni MR, Soares BG. Vaccines for preventing herpes zoster in older adults. Cochrane Database Syst Rev 2016;3:CD008858.

19 Bucher HC, Guyatt GH, Griffith LE, Walter SD. The results of direct and indirect treatment comparisons in meta-analysis of randomized controlled trials. J Clin Epidemiol 1997;50:683-91. doi:10.1016/S0895-4356(97)00049-8

20 Higgins JPT, ed. Cochrane Handbook for Systematic Reviews of Interventions Version 5.1.0. Cochrane Collaboration, 2011.

21 Shamseer L, Moher D, Clarke M, et al, PRISMA-P Group. Preferred reporting items for systematic review and meta-analysis protocols (PRISMA-P) 2015: elaboration and explanation. BMJ 2015;350:g7647. doi:10.1136/bmj.g7647

22 Tricco A, Zarin W, Cardoso R, et al. Efficacy, effectiveness, and safety of herpes zoster vaccines in individuals 50 years of age and older: a systematic review. PROSPERO 2017 CRD42017056389 www.crd. york.ac.uk/PROSPERO/display_record.php?ID=CRD42017056389.

23 Hutton B, Moher D, Cameron C. The PRISMA Extension Statement. Ann Intern Med 2015;163:566-7. doi:10.7326/L15-5144-2

24 Hoaglin DC, Hawkins N, Jansen JP, et al. Conducting indirecttreatment-comparison and network-meta-analysis studies: report of the ISPOR Task Force on Indirect Treatment Comparisons Good Research Practices: part 2. Value Health 2011;14:429-37. doi:10.1016/j.jval.2011.01.011

25 Jansen JP, Fleurence R, Devine B, et al. Interpreting indirect treatment comparisons and network meta-analysis for health-care decision making: report of the ISPOR Task Force on Indirect Treatment Comparisons Good Research Practices: part 1. Value Health 2011;14:417-28 doi:10.1016/j.jval.2011.04.002

26 Jansen JP, Trikalinos T, Cappelleri JC, et al. Indirect treatment comparison/network meta-analysis study questionnaire to assess relevance and credibility to inform health care decision making: an ISPOR-AMCP-NPC Good Practice Task Force report. Value Health 2014:17:157-73 doi:10.1016/j.jval 2014.01.004

27 Hutton B, Salanti G, Chaimani A, et al. The quality of reporting methods and results in network meta-analyses: an overview of reviews and suggestions for improvement. PLOS One 2014;9:e92508. doi:10.1371/journal.pone.0092508.

28 Hutton B, Salanti G, Caldwell DM, et al. The PRISMA extension statement for reporting of systematic reviews incorporating network meta-analyses of health care interventions: checklist and explanations. Ann Intern Med 2015;162:777-84. doi:10.7326/M14-2385

29 Stone PW. Popping the (PICO) question in research and evidencebased practice. Appl Nurs Res 2002;15:197-8. doi:10.1053/ apnr.2002.34181

30 McGowan J, Sampson M, Salzwedel DM, Cogo E, Foerster V, Lefebvre C. PRESS Peer Review of Electronic Search Strategies: 2015 Guideline Statement. J Clin Epidemiol 2016;75:40-6. doi:10.1016/j.jclinepi.2016.01.021

31 Matters G. a practical tool for searching health-related grey literature 2015 www.cadth.ca/resources/finding-evidence/grey-matters.

32 Synthesi.SR [program]: Knowledge Translation Program.

33 Higgins JP, Altman DG, Gøtzsche PC, et al, Cochrane Bias Methods Group. Cochrane Statistical Methods Group. The Cochrane Collaboration's tool for assessing risk of bias in randomised trials. BMJ 2011:343:d5928. doi:10.1136/bmi.d5928

34 Wells G, Shea B, O'Connell D, et al. The Newcastle-Ottawa Scale (NOS) for assessing the quality of nonrandomised studies in meta-analyses.

35 EPOC Resources for review authors: Effective Practice and Organisation of Care (EPOC)

36 Jansen JP, Crawford B, Bergman G, Stam W. Bayesian meta-analysis of multiple treatment comparisons: an introduction to mixed treatment comparisons. Value Health 2008;11:956-64. doi:10.1111/j.1524-4733.2008.00347.x 
37 Turner RM, Davey J, Clarke MJ, Thompson SG, Higgins JP. Predicting the extent of heterogeneity in meta-analysis, using empirical data from the Cochrane Database of Systematic Reviews. Int Epidemiol 2012;41:818-27. doi:10.1093/ije/dys041

38 Del Giovane C, Vacchi L, Mavridis D, Filippini G, Salanti G. Network meta-analysis models to account for variability in treatment definitions: application to dose effects. Stat Med 2013;32:25-39. doi:10.1002/sim.5512

39 ZOSTAVAX@ II [product monograph] Canada: Merck Canada; 2017 https://pdf.hres.ca/dpd_pm/00042265.PDF2018.

40 SHINGRIX [product monograph] Canada: GlaxoSmithKline; 2017 https://ca.gsk.com/media/1350788/shingrix_pm-2017-10-13. pdf2018.

41 Jansen JP, Naci H. Is network meta-analysis as valid as standard pairwise meta-analysis? It all depends on the distribution of effect modifiers. BMC Med 2013;11:159. doi:10.1186/1741-7015-11-159

42 White IR, Barrett JK, Jackson D, Higgins JP. Consistency and inconsistency in network meta-analysis: model estimation using multivariate meta-regression. Res Synth Methods 2012;3:111-25. doi:10.1002/jrsm.1045

43 Higgins JP, Jackson D, Barrett JK, Lu G, Ades AE, White IR. Consistency and inconsistency in network meta-analysis: concepts and models for multi-arm studies. Res Synth Methods 2012;3:98-110. doi:10.1002/jrsm.1044

44 Song F, Altman DG, Glenny AM, Deeks JJ. Validity of indirect comparison for estimating efficacy of competing interventions: empirical evidence from published meta-analyses. BMJ 2003;326:472. doi:10.1136/bmj.326.7387.472

45 Veroniki AA, Vasiliadis HS, Higgins JP, Salanti G. Evaluation of inconsistency in networks of interventions. Int Epidemiol 2013;42:332-45. doi:10.1093/ije/dys222

46 Petropoulou M, Nikolakopoulou A, Veroniki AA, et al. Bibliographic study showed improving statistical methodology of network meta-analyses published between 1999 and 2015. J Clin Epidemiol 2017;82:20-8. doi:10.1016/j.jclinepi.2016.11.002

47 CDC. Lesson 3: Measures of Risk: CDC; 2012 www.cdc.gov/ophss/csels/ dsepd/ss1978/lesson3/section6.html accessed March 29, 2018.

48 Riley RD, Higgins JP, Deeks JJ. Interpretation of random effects metaanalyses. BMJ 2011:342:d549. doi:10.1136/bmj.d549

49 Salanti G, Ades AE, Ioannidis JP. Graphical methods and numerical summaries for presenting results from multiple-treatment metaanalysis: an overview and tutorial. / Clin Epidemiol 2011;64:163-71. doi:10.1016/j.jclinepi.2010.03.016

50 Veroniki AA, Straus SE, Fyraridis A, Tricco AC. The rank-heat plot is a novel way to present the results from a network meta-analysis including multiple outcomes. / Clin Epidemiol 2016;76:193-9. doi:10.1016/j.jclinepi.2016.02.016

51 Chaimani A, Higgins JP, Mavridis D, Spyridonos P, Salanti G. Graphical tools for network meta-analysis in STATA. PLoS One 2013;8:e76654. doi:10.1371/journal.pone.0076654

52 Beals CR, Railkar RA, Schaeffer AK, et al. Immune response and reactogenicity of intradermal administration versus subcutaneous administration of varicella-zoster virus vaccine: an exploratory, randomised, partly blinded trial. Lancet Infect Dis 2016;16:915-22. doi:10.1016/S1473-3099(16)00133-X

53 Berger R, Trannoy E, Holländer G, Bailleux F, Rudin C, Creusvaux H. A dose-response study of a live attenuated varicella-zoster virus (Oka strain) vaccine administered to adults 55 years of age and older. J Infect Dis 1998;178(Suppl 1):S99-103. doi:10.1086/514265

54 Chlibek R, Bayas JM, Collins H, et al. Safety and immunogenicity of an AS01-adjuvanted varicella-zoster virus subunit candidate vaccine against herpes zoster in adults $>=50$ years of age. $J$ Infect Dis 2013;208:1953-61. doi:10.1093/infdis/jit365

55 Chlibek R, Smetana J, Pauksens K, et al. Safety and immunogenicity of three different formulations of an adjuvanted varicella-zoster virus subunit candidate vaccine in older adults: a phase II, randomized, controlled study. Vaccine 2014;32:1745-53. doi:10.1016/j. vaccine.2014.01.019

56 Cunningham AL, Lal H, Kovac M, et al, ZOE-70 Study Group. Efficacy of the Herpes Zoster Subunit Vaccine in Adults 70 Years of Age or Older. N Engl J Med 2016;375:1019-32. doi:10.1056/ NEJMoa1603800

57 Diez-Domingo J, Weinke T, Garcia de Lomas I, et al. Comparison of intramuscular and subcutaneous administration of a herpes zoster live-attenuated vaccine in adults aged $\geq 50$ years: a randomised non-inferiority clinical trial. Vaccine 2015;33:789-95. doi:10.1016/j.vaccine.2014.12.024

58 Gilderman LI, Lawless JF, Nolen TM, et al, Zostavax Protocol 010 Study Group. A double-blind, randomized, controlled, multicenter safety and immunogenicity study of a refrigerator-stable formulation of Zostavax. Clin Vaccine Immunol 2008;15:314-9. doi:10.1128/CVI.00310-07
59 GlaxoSmithKline Biologicals. A phase III, randomised, open-label, multicentre, clinical trial to assess the safety and immunogenicity of GSK Biologicals' $\mathrm{HZ} / \mathrm{su}$ vaccine when administered intramuscularly according to a 0,2-month schedule, a 0,6- month schedule or a 0,12-month schedule in adults aged 50 years or older. EU Clinical Trials, 2016

60 Hata A, Inoue F, Hamamoto Y, et al. Efficacy and safety of live varicella zoster vaccine in diabetes: a randomized, double-blind, placebo-controlled trial. Diabet Med 2016;33:1094-101. doi:10.1111/dme.13038

61 Kerzner B, Murray AV, Cheng E, et al. Safety and immunogenicity profile of the concomitant administration of ZOSTAVAX and inactivated influenza vaccine in adults aged 50 and older. J Am Geriatr Soc 2007; 55:1499-507. doi:10.1111/j.1532-5415.2007.01397.x

62 Lal H, Cunningham AL, Godeaux O, et al, ZOE-50 Study Group. Efficacy of an adjuvanted herpes zoster subunit vaccine in older adults. N Engl J Med 2015;372:2087-96. doi:10.1056/NEJMoa1501184.

63 Langan SM, Smeeth L, Margolis DJ, Thomas SL. Herpes zoster vaccine effectiveness against incident herpes zoster and post-herpetic neuralgia in an older US population: a cohort study. PLoS Med 2013;10:e1001420. doi:10.1371/journal.pmed.1001420

64 Leroux-Roels I, Leroux-Roels G, Clement F, et al. A phase 1/2 clinical trial evaluating safety and immunogenicity of a varicella zoster glycoprotein e subunit vaccine candidate in young and older adults. Infect Dis 2012;206:1280-90. doi:10.1093/infdis/jis497

65 Levin MJ, Schmader KE, Pang L, et al. Cellular and humoral responses to a second dose of herpes zoster vaccine administered 10 years after the first dose among older adults. J Infect Dis 2016;213:14-22. doi:10.1093/infdis/iiv480

66 MacIntyre CR, Egerton T, McCaughey M, et al. Concomitant administration of zoster and pneumococcal vaccines in adults $\geq 60$ years old. Hum Vaccin 2010;6:894-902. doi:10.4161/ hv.6.11.12852

67 Marin M, Yawn BP, Hales CM, et al. Herpes zoster vaccine effectiveness and manifestations of herpes zoster and associated pain by vaccination status. Hum Vaccin Immunother 2015;11:115764. doi:10.1080/21645515.2015.1016681

68 Merck Sharp \& Dohme Corp. A Study to Evaluate Immunity to Varicella Zoster Virus After Immunization With V212 Vaccine or Zostavax (V212-003). ClinicalTrialsgov, 2015: 1-9.

69 Murray A, Lawless J, Reisinger K, et al. Safety \& Tolerability of Zoster Vaccine in Adults $\geq 60$ Years Old. 2010. https://clinicaltrials.gov/ct2/ show/NCT00550745.

70 Russell AF, Parrino J, Fisher CL.Jr, et al. Safety, tolerability, and immunogenicity of zoster vaccine in subjects on chronic/ maintenance corticosteroids. Vaccine 2015;33:3129-34 doi:10.1016/j.vaccine.2015.04.090

71 Tseng HF, Harpaz R, Luo Y, et al. Declining Effectiveness of Herpes Zoster Vaccine in Adults Aged $\geq 60$ Years. J Infect Dis 2016;213:1872-5. doi:10.1093/infdis/jiw047

72 Tyring SK, Diaz-Mitoma F, Padget LG, et al, Protocol 009 Study Group. Safety and tolerability of a high-potency zoster vaccine in adults $>/=50$ or years of age. Vaccine 2007;25:1877-83. doi:10.1016/j.vaccine.2006.10.027

73 Vermeulen JN, Lange JMA, Tyring SK, et al. Safety, tolerability, and immunogenicity after 1 and 2 doses of zoster vaccine in healthy adults $\geq 60$ years of age. Vaccine 2012;30:904-10 doi:10.1016/j.vaccine.2011.11.096

74 Vesikari T, Hardt R, Rümke HC, et al. Immunogenicity and safety of a live attenuated shingles (herpes zoster) vaccine (Zostavax $®$ ) in individuals aged $\geq 70$ years: a randomized study of a single dose vs. two different two-dose schedules. Hum Vaccin Immunother 2013;9:858-64. doi:10.4161/hv.23412

75 Vink P, Shiramoto M, Ogawa M, et al. Safety and immunogenicity of a Herpes Zoster subunit vaccine in Japanese population aged $\geq 50$ years when administered subcutaneously vs. intramuscularly. Hum Vaccin Immunother 2017;13:574-8. doi:10.1080/21645515. 2016.1232787

76 Zhang J, Xie F, Delzell E, et al. Association between vaccination for herpes zoster and risk of herpes zoster infection among older patients with selected immune-mediated diseases. JAMA 2012;308:43-9. doi:10.1001/jama.2012.7304

77 GSK Clinical Study Register. A phase II, single-blind, randomized, controlled, multicentre vaccination study to evaluate the safety and immune response of the GSK Biologicals Zoster vaccine, gE/ASO1B, and to compare 3 doses of gE with ASO1B adjuvant in healthy elderly subjects, aged 60 to 69 years and 70 years and above, 2010 .

78 GlaxoSmithKline Biologicals. Ensayo clínico de vacunación fase III, aleatorizado, observador-ciego, controlado con placebo, multicéntrico para evaluar la eficacia profiláctica, seguridad e inmunogenicidad de la vacuna gE/ASO1B de GSK Biologicals administrada por vía intramuscular con. EU Clinical Trials, 2016. 
79 Langan SM, Thomas SL, Smeeth L, Margolis DJ, Nitsch D. Zoster vaccination is associated with a reduction of zoster in elderly patients with chronic kidney disease. Nephrol Dial Transplant 2016;31:2095-8. doi:10.1093/ndt/gfv432

80 Schmader KE, Oxman MN, Levin MJ, et al, Shingles Prevention Study Group. Persistence of the efficacy of zoster vaccine in the shingles prevention study and the short-term persistence substudy. Clin Infect Dis 2012;55:1320-8. doi:10.1093/cid/cis638

81 Simberkoff MS, Arbeit RD, Johnson GR, et al, Shingles Prevention Study Group. Safety of herpes zoster vaccine in the shingles prevention study: a randomized trial. Ann Intern Med 2010;152:54554. doi:10.7326/0003-4819-152-9-201005040-00004

82 Oxman MN, Levin MJ, Shingles Prevention Study Group. Vaccination against Herpes Zoster and Postherpetic Neuralgia. J Infect Dis 2008:197(Suppl 2):S228-36. doi:10.1086/522159

83 Schmader KE, Johnson GR, Saddier P, et al, Shingles Prevention Study Group. Effect of a zoster vaccine on herpes zoster-related interference with functional status and health-related quality-oflife measures in older adults. J Am Geriatr Soc 2010;58:1634-41. doi:10.1111/j.1532-5415.2010.03021.x

84 Ahnn S. FDA Statistical Review and Evaluation Document for the Vaccines and Related Biological Products Advisory Committee (VRBPAC). Protocol 2005;004:1-14.

85 Levin MJ, Oxman MN, Zhang JH, et al, Veterans Affairs Cooperative Studies Program Shingles Prevention Study Investigators. Varicella-zoster virus-specific immune responses in elderly recipients of a herpes zoster vaccine. J Infect Dis 2008;197:825-35. doi:10.1086/528696

86 Levin M, Oxman M, Bobrove A, et al. GER-3. Dose-Ranging Safety and Immunogenicity Study of Live Attenuated Varicella-Zoster Virus Vaccine (Oka/Merck) Administered to Adults 60 Years of Age or Older. South Med I 2005;98:S55d oi:10.1097/00007611-200510001-00151.

87 Levin MJ, Schmader KE, Gnann JW, et al. Varicella-zoster virus-specific antibody responses in 50-59-year-old recipients of zoster vaccine. J Infect Dis 2013;208:1386-90. doi:10.1093/infdis/jit342

88 Tseng HF, Luo Y, Shi J, et al. Effectiveness of Herpes Zoster Vaccine in Patients 60 Years and Older With End-stage Renal Disease. Clin Infect Dis 2016;62:462-7.

89 Tseng HF, Smith N, Harpaz R, Bialek SR, Sy LS, Jacobsen SJ. Herpes zoster vaccine in older adults and the risk of subsequent herpes zoster disease. JAMA 2011;305:160-6. doi:10.1001/jama.2010.1983
90 Tseng HF, Tartof S, Harpaz R, et al. Vaccination against zoster remains effective in older adults who later undergo chemotherapy. Clin Infect Dis 2014;59:913-9. doi:10.1093/cid/ciu498

91 Tseng HF, Chi M, Smith N, Marcy SM, Sy LS, Jacobsen SJ. Herpes zoster vaccine and the incidence of recurrent herpes zoster in an immunocompetent elderly population. J Infect Dis 2012;206:190-6. doi:10.1093/infdis/jis334

92 Sanofi Pasteur MSDSNC. An open-label, randomised, phase 3, comparative, multi-centre study of the immunogenicity and safety of a 1-dose regimen and different 2-dose regimens of a Zoster vaccine (Live), ZOSTAVAX®, in subjects >=70 years of age, 2009:1-13. https://clinicaltrials.gov/ct2/show/NCT00561080.

93 GlaxoSmithKline. Safety and Immunogenicity Study of GSK Biologicals ‘ Herpes Zoster Subunit (HZ / su) Vaccine GSK1437173A When Administered Subcutaneously Intramuscularly in Adults Aged $\geq$ 50 Years. ClinicalTrialsgov, 2017.

94 Zhang J, Delzell E, Xie F, et al. The use, safety, and effectiveness of herpes zoster vaccination in individuals with inflammatory and autoimmune diseases: a longitudinal observational study. Arthritis Res Ther 2011;13:R174. doi:10.1186/ar3497

95 Murray AV, Reisinger KS, Kerzner B, et al. Safety and tolerability of zoster vaccine in adults $\geq 60$ years old. Hum Vaccin 2011;7:1130-6. doi:10.4161/hv.7.11.17982

96 Comparison of a Live Herpes Zoster Vaccine and a Recombinant Vaccine in 50-59 and 70-85 Year Olds. ClinicalTrials.gov: U.S National Library of Medicine.

97 Dooling KL, Guo A, Patel M, et al. Recommendations of the Advisory Committee on Immunization Practices for Use of Herpes Zoster Vaccines. MMWR Morb Mortal Wkly Rep 2018;67:103-8. doi:10.15585/mmwr.mm6703a5

98 McDonald BM, Dover DC, Simmonds KA, Bell CA, Svenson LW, Russell ML. The effectiveness of shingles vaccine among Albertans aged 50 years or older: A retrospective cohort study. Vaccine 2017;35:6984-9. doi:10.1016/j.vaccine.2017.10.067

99 Yawn BP. Post-shingles neuralgia by any definition is painful, but is it PHN? Mayo Clin Proc 2011;86:1141-2. doi:10.4065 mcp.2011.0724

Supplementary information: Appendices S1-S23 and references 